\title{
Silent Free Perforation of Duodenal Ulcer in an Elderly Patient Presenting with Melena: Management Directed by Upper Endoscopy and Percussion of the Liver
}

A 70-year-old man was admitted to hospital having had one tarry stool 6 hours beforehand. There was no history of abdominal pain, vomiting, or use of nonsteroidal anti-inflammatory drugs (NSAIDs). His blood pressure was normal and abdominal wall tenderness was absent. Laboratory tests showed mild anemia (hemoglobin $102 \mathrm{~g} / \mathrm{l})$. An upper endoscopy revealed deep ulceration on the anterior bulbar wall with visible liver in the depth of the picture (Figure 1). Because of absence of overt symptoms and signs of acute abdomen confined perforation was suspected. During and after the examination the patient had no pain. Percussion of the liver, which was not done previously, showed absence of liver dullness and suggested free perforation. Radiographic examination showed pneumoperitoneum. Surgery, performed 24 hours after the patient's admission to the hospital, confirmed the perforation of duodenal ulcer. The patient was discharged on the 11th postoperative day.

The typical presentation of free peptic ulcer perforation is frequently less intense in elderly patients $[1,2]$, especially patients in poor medical condition, with massive gastrointestinal bleeding [3], or taking NSAIDs [4]. Symptoms of free peptic ulcer perforation were absent in this patient with moderate gastrointestinal hemorrhage. He was a healthy-appearing old man in whom there was no explanation for silent free perforation except elderly age. The endoscopic diagnosis of ulcer perforation is not frequent, because endoscopy is considered an inadequate diagnostic tool

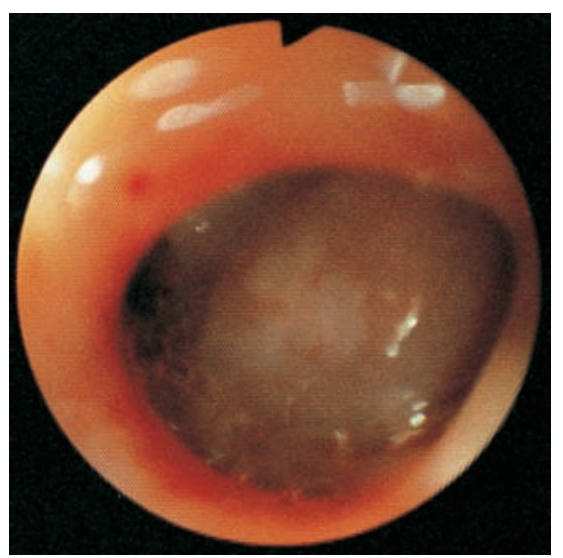

Figure 1 Endoscopic view of perforated duodenal ulcer. Deep ulceration was found on the anterior bulbar wall with visible liver in the depth of the picture and minor superficial hemorrhage on the anterior ulcer margin by many authors [5]. Insufflation during upper endoscopy could aggravate free perforation and even convert a confined perforation to a free one. With a minimal level of insufflation and an operating theatre on the alert, the role of endoscopy in the management of suspected ulcer perforation could be reconsidered. Percussion of the liver also should not be overlooked in the diagnostic algorithm of ulcer perforation.

\section{Mimica}

Division of Internal Medicine,

University Clinic Mostar, Mostar,

Bosnia-Herzegovina

\section{References}

${ }^{1}$ Runyon BA. Surgical peritonitis and other diseases of the peritoneum, mesentery, omentum and diaphragm. In: Sleisenger MH, Fordtran JS (eds). Gastrointestinal disease. Philadelphia: WB Saunders, 1993: 2004-2014

${ }^{2}$ Ridge JA, Way LW. Acute abdominal pain in the elderly. In: Sleisenger $\mathrm{MH}$, Fordtran JS (eds). Gastrointestinal disease. Philadelphia: WB Saunders, 1993: $150-161$
${ }^{3}$ Dasmahapatra KS, Suval W, Machiedo GW. Unsuspected perforation in bleeding duodenal ulcers. Am Surg 1988; 54: 19-21

${ }^{4}$ Festen HP. Gastrointestinal lesions during treatment with non-steroidal anti-inflammatory drugs (NSAIDs). Neth $\mathrm{J}$ Med 1989; 35: 327-333

${ }^{5}$ Hammer HF, Krejs G. Acute abdomen. In: Porro GB, Cremer M, Krejs G, et al. (eds). Gastroenterology and hepatology. Maidenhead: McGraw-Hill, 1999: 4953

Corresponding Author M. Mimica, M.D.

Interna Klinika Bijeli brijeg

Kardinala Stepinca bb

88000 Mostar

Bosnia-Herzegovina

Fax: $\quad+387-36-326-426$

E-mail: mladen.mimica@tel.net.ba 